\title{
F-18 Sodium Fluoride Positron Emission Tomography and Magnetic Resonance Imaging
}

National Cancer Institute

\section{Source}

National Cancer Institute. F-18 Sodium Fluoride Positron Emission Tomography and Magnetic Resonance Imaging. NCI Thesaurus. Code C148079.

An imaging procedure that combines F-18 sodium fluoride PET with an MRI scan to overlay activity data onto detailed anatomic images. 